\title{
Outcomes of Eclectic Voice Therapy Program in the Treatment of Hyperfunctional Voice Disorders: A Preliminary Study
}

\author{
Pebbili Gopikishore and M. Pushpavathi \\ Department of Speech Language Pathology, AIISH, India
}

Submission: May 17, 2017; Published: May 30, 2017

*Corresponding author: Pebbili Gopikishore, Lecturer in Speech Pathology, AIISH, Mysuru, India, Email: gopiaslp@gmail.com

\section{Abstract}

The objective of this study was to investigate the treatment effects of an eclectic voice therapy (EVT) program consisting of individualized vocal hygiene education, breath support exercises, use of voice with forward focus, and laryngeal manual therapy in the management of individuals with Hyperfunctional voice disorders (HFVD). The study was based on hypotheses that EVT program would improve voice quality in individuals with HFVD. Single-subject, prospective, time-series design was used to investigate this hypothesis. Five individuals diagnosed to have HFVD by a team of Laryngologist and Speech Language Pathologist were considered for the study. A trained SLP provided an average of 10 sessions (each of 40 minutes duration) of voice therapy to all the participants with emphasis on vocal hygiene education and optimization of each of the subsystems of voice production. Objective measurement of voice quality using Dysphonia Severity Index (DSI) served as outcome measure. DSI measures were obtained before commencing EVT program and after completion of every two sessions of therapy to track the changes. Results indicated marked increase DSI scores following EVT program. Positive effects of the EVT program can be attributed to the vocal awareness, optimization of each of the subsystems of voice production and the enhancement of balance among them. Result of this pilot study supports use of EVT as an approach in the treatment of HFVD.

Abbreviations: EVT: Eclectic Voice Therapy; HFVD: Hyperfunctional Voice Disorders; DSI: Dysphonia Severity Index; AIISH: All India Institute of Speech and Hearing; MDVP: Multi Dimensional Voice Program; CSL: Computerized Speech Lab; SLP: Speech Language Pathologist

\section{Introduction}

Hyperfunctional dysphonia is characterized by excessive phonatory effort [1]. The excessive muscular effort can be evident along the length of the vocal tract involving the articulatory muscles, the intrinsic and extrinsic laryngeal muscles, including the dimensions of the resonators. The resulting effect of this vocal behavior places physical stresses on the anatomy and physiology of the vocal tract, causing undesirable changes in its function and, in some cases, trauma to the vocal folds. Hyperfunctional voice disorders (HFVD) are the voice disorders that are not associated with neurological, malignant, dysplastic, inflammatory, immunologic endocrine or psychiatric conditions or with laryngeal trauma or injury [2]. Different types and degrees of abnormal and/or excessive muscle tension in the laryngeal muscles during phonation are considered as essential features for HFVD [2].

The origin of HFVD is usually multifactorial in nature because of the overlay of causal and contributing factors. Vocal hyperfunction is common among the vocal performers, for example, singers, actors, and teachers due to excessive vocal loading, lifestyle, working ambiance, and psychological stress. Baker [3] emphasized the multilayered involvement of psychological issues such as dispositional personality traits, coping styles, life events and difficulties as well as poorly regulated muscle tension in the genesis of HFVD. The origin of primary HFVD is abnormal laryngeal muscle activity [4]. The abnormal muscle activity in HFVD is attributed to a variety of potentially overlapping sources, including psychological and personal factors, technical misuses of the voice when extra demands are placed upon it, increased muscle tone in the pharyngolarynx secondary to laryngopharyngeal reflux, and the learned adaptations following a disruption such as an upper respiratory tract infection.

Based on the multifactorial etiological features of HFVD, various therapy approaches have been used for intervention with different philosophies $[3,5,6]$. Researchers used physicalmanipulative voice therapy paradigm [5] and Psychosocial 
approaches [3]. Behavioral management of extrathoracic airway hyper responsiveness and chronic cough was considered as a potentially valuable component of treatment for HFVD [6]. Three treatment approaches predominantly psychosocial approach, behavioral voice therapy, and a more physicalmanipulative voice therapy program were outlined for the treatment of HFVD in a review article [7]. In addition, treatment of LPR was discussed as a key factor in the resolution of HFVD. However, the authors concluded that although, the voice therapy programs comprising of indirect approaches (e.g., vocal hygiene) along with direct techniques (e.g., behavioral and physicalmanipulative approaches) are effective for HFVD.

Eclectic voice therapy programs comprising of vocal hygiene education along with specific symptomatic voice therapy approaches have been used successfully in the treatment of voice disorders $[8,9]$. For instance, the effect of a voice therapy consisting of vocal hygiene lectures, breathing exercises, chant technique on two groups of teachers with normal and pathological voices (associated with vocal nodules, incomplete adduction of the glottis during phonation, or both) was investigated [8]. The voice therapy included eight therapy sessions of 45-minute duration with the first session on vocal hygiene followed by seven sessions of respiratory and phonatory exercises. The measures considered were the perceptual analysis of voice quality by speech pathologists on a rating scale where one end of the scale was labeled 'Normal' and the other was labeled 'Severe', and the acoustic analysis of the vowels /a/, /i/, /u/ to obtain the fundamental frequency, jitter, shimmer, noise-to-harmonic ratio, voice turbulence index. Results indicated an improvement in the voice quality in both the normal and pathological groups, however, with pronounced improvement in the pathological group than in a non-pathological group.

Considering multi factorial etiology of the HFVD including vocal abuse, compromised lifestyles, abnormal laryngeal muscle activity, it was hypothesized that an eclectic voice therapy program could promote better prognosis in individuals with HFVD. This assumption was further supported by the effectiveness of these combination approaches reported in the voice therapy literature. Given the dearth of literature in verifying the efficacy of voice therapy in individuals with HFVD and the success of eclectic voice therapy programs, it is essential to formulate a systematic voice therapy program and to investigate its efficacy in the context of various voice disorders involving vocal hyperfunction. Therefore, the current study was aimed at investigating the efficacy of a voice therapy programme on voice quality of individuals with hyperfunctional voice disorder as measured objectively on dysphonia severity index (DSI).

\section{Methods and Materials}

\section{a) Participants}

A prospective single-subject time series design study was carried out on five females in the age range of 19-45 years diagnosed with HFVD by a team consisting of Laryngologist, Phonosurgeon and Speech Language Pathologist (SLP). Detailed participant characteristics are given in Table 1.

Table 1: Details of the participants.

\begin{tabular}{|c|c|c|c|c|}
\hline Name & Age & Profession & $\begin{array}{l}\text { Voice related } \\
\text { habbits }\end{array}$ & Diagnosis \\
\hline A & 38 & Teacher & $\begin{array}{l}\text { Extrovert and } \\
\text { talkative }\end{array}$ & $\begin{array}{c}\text { Moderate hoarse voice with early vocal } \\
\text { nodules }\end{array}$ \\
\hline B & 32 & Teacher & - & $\begin{array}{c}\text { Moderate hoarse voice with muscle tension } \\
\text { dysphonia (MTD) }\end{array}$ \\
\hline $\mathrm{C}$ & 28 & $\begin{array}{l}\text { Commercial tax } \\
\text { officer }\end{array}$ & Singing (Classical) & $\begin{array}{l}\text { Mild hoarse voice with early vocal nodules, } \\
\text { MTD }\end{array}$ \\
\hline $\mathrm{D}$ & 42 & Home maker & - & Moderate hoarse voice with vocal nodules \\
\hline E & 28 & Teacher & - & $\begin{array}{l}\text { Mild hoarse voice with early vocal nodules, } \\
\text { MTD }\end{array}$ \\
\hline
\end{tabular}

\section{b) Diagnosing HFVD}

The participants were evaluated by a team of Laryngologist and Speech Language Pathologist experienced in treating voice disorders. Laryngologist's evaluation included visualizing the laryngeal and perilaryngeal structures using rigid 70-degree scope attached to Xion Videostroboscopy from Dr. Speech. The participant was instructed to sit with straight back, slightly elevated neck, protruded tongue and was asked to phonate /i/ on indication. Following the defogging and white balance of the scope, the participant was instructed to phonate vowel /i/. A 5-10 seconds recording was obtained under videolaryngoscopic as well as videostroboscopic conditions. The sample was analyzed with emphasis on appearance and movement of glottic and supraglottic structures at rest and on phonation. The glottic parameters recorded included the appearance of the anterior and posterior commissure of vocal folds, edge of the vocal 
folds and glottic closure pattern. The documented supraglottic parameters included the appearance and movement of the epiglottis, aryepiglottic folds, and ventricular folds.

The SLPs assessment involved obtaining a detailed history of the participant's voice problem, perceptual evaluation of the voice quality using GRBAS rating scale, and the manual evaluation of the laryngeal, perilaryngeal and respiratory mechanisms for muscular hyperfunction. The laryngeal palpatory evaluation was performed following the procedure described in literature [10]. The diagnosis of hyperfunctional voice disorder was made following consensus by the team members and by correlating the clinical findings with the participant's history of voice problem. Individuals with evidence of active laryngeal or pharyngeal infections, mass-occupying lesions of vocal cords, neuropathology such as vocal fold paralysis, vocal tremor, and dysarthria; individuals with spasmodic dysphonia of psychogenic or neurogenic origin; individuals with endocrinal disturbances or hearing problems; individuals with history or presence of cardiovascular disorders, cervical injuries, spondylitis, emotional or psychological disturbances were excluded from the study.

\section{c) Voice therapy program}

A thorough review of recent voice therapy programs was done to systematically develop the eclectic therapy program for HFVD. Considering the reports from the literature, a voice therapy program was developed that focused firstly on improving participant's vocal hygiene awareness, secondly facilitating coordination between the respiratory and phonatory systems with the aim of developing vocal efficiency, thirdly reducing excessive muscle tension in the laryngeal and perilaryngeal region using Laryngeal Manual Therapy [10] and finally with focus on improving the quality of voice by promoting forward focus. Ten therapy sessions each of 40 minutes duration, lasted for a period of 3-6 weeks was conducted by an SLP experienced in the area of voice. Initial two therapy sessions were focused on improving participant's competence regarding the normal and abnormal vocal production, factors that influence the voice production, and regarding the current condition of participant's voice along with the plausible factors that lead to the condition.

This was done using animations on voice production, recorded laryngoscopic videos of normal and the participants recorded laryngoscopic video. The subsequent sessions were conducted with emphasis on developing balance across the respiratory, phonatory and resonatory subsystems of voice production. This was performed using audiovisuals initially and followed by the live demonstration. Following each session, the participant was instructed to practice the respiratory and resonatory exercises for 15 minutes twice a day. Table 2 provides information on the systematic application of the voice therapy program during the therapy sessions. Before commencement of the voice therapy program, an informed consent was obtained from all the participants included in the study.

Table 2: Details of the implementation of voice therapy program.

\begin{tabular}{|c|c|c|c|}
\hline Component of therapy program & Activities & $\begin{array}{c}\text { Duration of demonstration or } \\
\text { practice }\end{array}$ & Mode of demonstration \\
\hline Vocal Hygiene Education & $\begin{array}{l}\text { a) Informal one-to-one lecture } \\
\text { using audiovisuals. }\end{array}$ & Initial 2 sessions & $\begin{array}{l}\text { Discussion and audiovisual/video } \\
\text { clippings }\end{array}$ \\
\hline \multirow{2}{*}{ Respiratory System } & $\begin{array}{l}\text { To develop abdominal } \\
\text { pattern of breathing }\end{array}$ & \multirow{2}{*}{15 minutes per session } & \multirow{2}{*}{$\begin{array}{l}\text { Live demonstration and } \\
\text { audiovisual/video clippings }\end{array}$} \\
\hline & $\begin{array}{cc}\text { b) } & \text { To develop } \\
\text { respiratory-phonatory control }\end{array}$ & & \\
\hline \multirow{5}{*}{ Laryngeal system } & $\begin{array}{l}\text { Laryngeal palpatory evaluation } \\
\text { and Laryngeal Manual Therapy } \\
\text { (LMT) (10) }\end{array}$ & \multirow{5}{*}{$\begin{array}{l}15 \text { minutes per session (with } \\
\text { a repetition in the session if } \\
\text { required) }\end{array}$} & \multirow{5}{*}{$\begin{array}{l}\text { Live demonstration and } \\
\text { audiovisual/video clippings }\end{array}$} \\
\hline & Laryngeal manual therapy: & & \\
\hline & $\begin{array}{l}\text { a) Rotator massaging of the } \\
\text { sternocleidomastoid muscles }\end{array}$ & & \\
\hline & $\begin{array}{l}\text { b) Kneading of the } \\
\text { supralaryngeal region }\end{array}$ & & \\
\hline & $\begin{array}{l}\text { c) Gently pulling down the } \\
\text { larynx (if high held) }\end{array}$ & & \\
\hline Resonatory system & $\begin{array}{c}\text { To develop on "Forward focus" } \\
\text { and kinesthetic feedback to } \\
\text { monitor front focus. }\end{array}$ & 10 minutes per session & $\begin{array}{l}\text { Live demonstration and } \\
\text { audiovisual/video clippings }\end{array}$ \\
\hline
\end{tabular}

Outcome measures: Dysphonia severity index (DSI) [11] was used for documenting the therapeutic outcomes. The DSI is the weighted combination of acoustic and aerodynamic parameters of voice, i.e. highest frequency (F0- High in $\mathrm{Hz}$ ), lowest intensity (I-low in $\mathrm{dB}$ ), maximum phonation time (MPT in seconds) and jitter (\%) and it is constructed using the formula DSI $=0.13 \times \mathrm{MPT}+0.0053 \times \mathrm{F}(0)$-High $-0.26 \times \mathrm{I}$-Low $-1.18 \mathrm{x}$ Jitter $(\%)+12.4$. The score ranges from +5 for perceptually normal voices towards -5 for severely dysphonic voices. 


\section{Global Journal of Otolaryngology}

Computerized Speech Lab (CSL) 4500 by Kay PENTAX was used to obtain all the parameters using the procedure given in the literature [11]. To obtain maximum phonation time, the participant was instructed to sit in a comfortable posture and sustain the vowel /a/ at habitual pitch and loudness to a microphone connected to the CSL. The procedure was modeled by the experimenter and the participant was visually encouraged during his turn of vowel prolongation. The length of the sustained vowel (in seconds) was measured by placing the cursors at the either end of the voicing sample on the recording window of Computerized Speech Lab (CSL). Initially, two trials of MPT was obtained followed by three test recordings of MPT and the best (longest duration) of the three test recordings was retained for further analysis and descriptions.

The highest frequency and the lowest intensity were measured with the aid of voice range profile (VRP) from CSL (4500). The recordings of Fo-high and I-low were taken with the instrument in VRP mode and with a table mounted microphone kept at a constant distance of $10 \mathrm{~cm}$ from the mouth. For obtaining highest frequency, the participant was instructed to glide the vowel /a/. The participant was further instructed and encouraged to use the visual feedback from the display on the computer screen to produce the best possible highest frequency. Initially, two trials were obtained followed by three test recordings and the best of the three highest frequencies on the test recordings were considered for further analysis. For obtaining lowest intensity (I-low), the participant was instructed to produce the vowel /a/ as soft as possible. The recording was performed using the CSL in VRP mode and with the device Switch craft (to obtain the absolute intensity measures by nullifying the effect of pre-amplification) connected to the microphone. Three test recordings were obtained followed by two trials and the lowest of the three lowest intensities on test recordings was considered for further analysis.

Jitter (\%) was determined with the aid of Multi Dimensional Voice Program (MDVP) module of CSL. The participant was instructed to sit in a comfortable posture and sustain the vowel /a/ at habitual pitch and loudness to a table mounted microphone kept at a constant distance of $10 \mathrm{~cm}$ from participant's mouth and connected to the hardware of CSL. The recording was done at $44 \mathrm{kHz}$ sampling rate in the window length of 10 seconds. A mid vowel segment of 3 seconds duration was selected for analysis by avoiding the initial and final segments. The jitter (\%) obtained from the analysis was used for further calculations.

With the obtained values, the DSI was constructed following the equation DSI $=0.13 \mathrm{x}$ MPT(s) $+0.0053 \times$ Fo-high $(\mathrm{Hz})-0.26$ $x$ I-low $(\mathrm{dB})-1.18 \mathrm{x}$ jitter $(\%)+12.4$ using an excel sheet. The DSI values were obtained before commencing therapy program and after the completion of every two sessions of voice therapy. The values were plotted in the form of graphical representation and the parameters were compared across the sessions for DSI scores.

\section{Results and Discussion}

In the current study, it was hypothesized that an eclectic voice therapy program comprising of patient education along with the systematic implementation of symptomatic voice therapy approaches could promote better prognosis in individuals with HFVD. In order to verify the hypothesis, five females in the age range of 28-42 years diagnosed with HFVD by a team consisting of a Laryngologist and a Speech Language Pathologist were considered for the study. The outcome of the therapy was documented before commencing the therapy (baseline) and following every two sessions during the therapy using the objective parameter dysphonia severity index (DSI). Results of the study are depicted in the line diagram figure I, where DSI scores (on the y-axis) is plotted against the number of particular observation (on the x-axis). The first observation of each participant in the figure represents baseline DSI measurement followed by the other observations which were obtained consecutively following every two sessions.

DSI has been considered as a robust and reliable measure and has been used frequently in the several efficacy studies. This parameter has been reported as a good correlate of perceptual dysphonia severity. In the current study, this parameter is used to document the changes in voice quality across the therapy sessions in participants with hyperfunctional voice disorders. It may be observed from the Figure 1 that the each of the participant differed in their baseline DSI scores indicating the differences in their baseline severity of voice disorder. For instance, participants A and D had baseline DSI scores below zero indicating more severe voice disorder than compared to $\mathrm{C}$ and E participants with relatively higher baseline DSI scores. These baseline DSI scores are going well with their perceptual voice quality before the commencement of therapy.

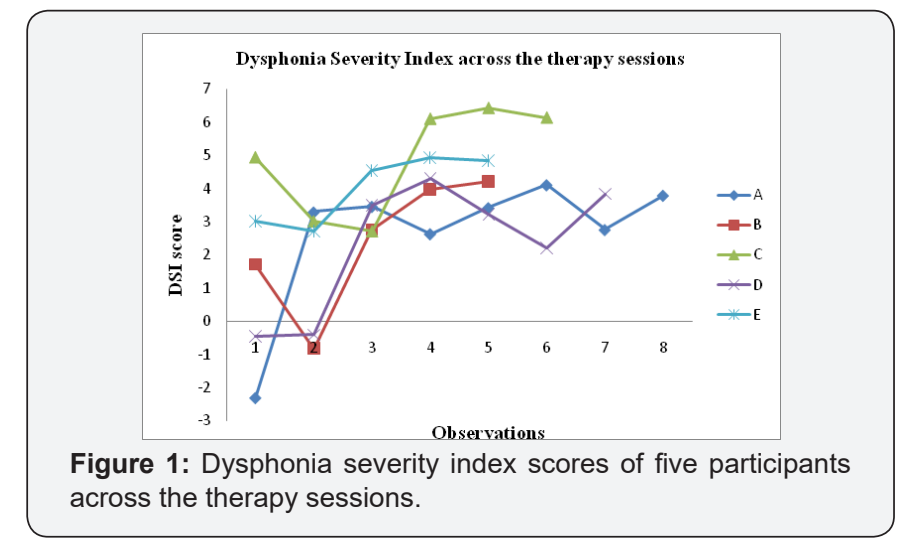

Following establishing the baseline DSI, the eclectic voice therapy (EVT) program was commenced with first two sessions focusing on the vocal hygiene education. Following this, laryngeal manual therapy, breathing exercises, and resonant voice therapy were practiced in the session. It is evident from the Figure 1 that the DSI score of all the participants had improved with the proposed EVT program. Despite the lack of consistency in improvement with each observation, the overall 
DSI score towards the end of their therapy program is markedly at a higher level compared to their baselines, thus indicating the positive effect of the proposed EVT program. This finding is in consonance with the findings reported in the literature [8-10] who reported significant improvement in voice quality with eclectic voice therapy approaches and laryngeal manual therapy respectively.

The DSI value of the participants following voice therapy program ranged from 3.79 to 6.14 which is towards the average value of DSI in Indian females [12]. Four out of the five participants achieved this average DSI value of phononormic females by the end of sixth sessions of EVT program, whereas participant A took 10 sessions to achieve this level of DSI. Three out of five participants were able to maintain this level of progress following six sessions; however, two other participants had a slight dip in DSI scores before achieving this normative level again.

The magnitude and the timing of improvement of voice quality as measured with DSI varied slightly in each participant. Participants B, C, D and E followed a similar trend in change of voice quality following therapy. As may be observed from the figure, the voice quality in all these four participants deteriorated initially (unaltered for D) with voice therapy and moved positively only after their second therapy session i.e. at third observation. This could be attributed to the sensitivity that the participants gained following vocal hygiene education in the first two sessions. During these two sessions, the participants were educated on vocal hygiene aspects such as the ill effects of producing effortful voice, phonating on end of the breath, use of breathy attack for initiation of phonation. Therefore it may be possible that the participants were not using the abnormal compensations, thus reducing the maximum phonation time, highest f0 and thus reducing the overall DSI value. The sharp increase in DSI value following during the second observation could further be due to the introduction of systematic implementation of symptomatic voice therapy exercises. Similar finding with immediate positive effects in voice quality following a single session of laryngeal manual therapy was reported in the literature [10]. However, the participant ' $A$ ' did not follow this trend and shown drastic improvement following vocal hygiene education itself, the magnitude of which was maintained across the sessions.

\section{Conclusion}

The findings of the preliminary study suggest that combinatory approach with vocal hygiene education along with the systematic implementation of symptomatic approaches targeting each of the subsystems of voice production improves voice quality in individuals with hyper functional voice disorders. Further, maximum improvement in the voice was observed following the four sessions of voice therapy after which the prognosis was minimal. While four out of the five participants achieved average DSI value of phononormic females by the end of sixth sessions of EVT program, one of the participants took 10 sessions to achieve this level of DSI.

\section{Compliance with ethical standards}

a) Conflict of interest: We the authors of this research article declare no conflict of interest.

b) Ethical approval: This study was conducted with the clearance from All India Institute of Speech and Hearing (AIISH) Biobehavioral Ethics Committee and with the written consent from the parents/ caregivers. They were provided with information about the aim, objectives, method of the research and approximate duration of testing.

Informed consent was obtained from all individual participants included in the study.

\section{References}

1. Boone DR, McFarlane SC (1988) The voice and voice therapy ( $4^{\text {th }}$ edn.). Englewood Cliffs, Prentice-Hall, New Jersey, USA.

2. Verdolini K, Rosen CA, Branski RC (2006) Classification manual for voice disorders - 1. Mahwah, Lawrence Erlbaum Associates, NJ, USA.

3. Baker J (2008) The role of psychogenic and psychosocial factors in the development of functional voice disorders. International Journal of Speech-Language Pathology 10(1): 210-230.

4. Roy N (2008) Assessment and treatment of musculoskeletal tension in hyperfunctional voice disorders. International Journal of SpeechLanguage Pathology 10(4): 195-209.

5. Aronson AE (1990) Psychogenic voice disorders. Clinical voice disorders: An interdisciplinary approach ( $3^{\text {rd }}$ edn.) Thieme, New York, USA, pp. 314-315.

6. Vertigan AE, Gibson PG, Theodoros DG, Winkworth AL (2008) The role of sensory dysfunction in the development of voice disorders, chronic cough, and paradoxical vocal fold movement. International Journal of Speech-Language Pathology 10(4): 231-244.

7. Oates J, Winkworth A (2008) Current knowledge, controversies and future directions in hyperfunctional voice disorders. International Journal of Speech-Language Pathology 10(4): 267-277.

8. Amir O, Dukas M, Shnaps-Baum R (2005) The effect of a 'voice course' on the voices of people with and without pathologies: preliminary observations. Logopedics Phoniatrics Vocology 30(2): 63-71.

9. Wingate JM, Brown WS, Shrivastav R, Davenport P, Sapienza CM (2007) Treatment outcomes for professional voice users. Journal of Voice 21(4): 433-449.

10. Mathieson L, Hirani SP, Epstein R, Baken RJ, Wood G, Rubin JS (2009) Laryngeal manual therapy: a preliminary study to examine its treatment effects in the management of muscle tension dysphonia. Journal of Voice 23(3): 353-366.

11. Wuyts FL, Molenberghs G, Remacle M, Heylen L, Millet B, et al. (2000) The Dysphonia Severity Index: An Objective Measure of Vocal Quality Based on a Multiparameter Approach. Journal of Speech, Language, and Hearing Research 43(3): 796-809.

12. Jayakumar T Savithri SR (2012) Effect of geographical and ethnic variation on Dysphonia Severity Index. A study of Indian population. Journal of Voice 26(1): e11-e16. 
This work is licensed under Creative

Commons Attribution 4.0 License

\section{Your next submission with Juniper Publishers} will reach you the below assets

- Quality Editorial service

- Swift Peer Review

- Reprints availability

- E-prints Service

- Manuscript Podcast for convenient understanding

- Global attainment for your research

- Manuscript accessibility in different formats

( Pdf, E-pub, Full Text, Audio)

- Unceasing customer service

Track the below URL for one-step submission https://juniperpublishers.com/online-submission.php 